\title{
РЕЦЕНЗИИ
}

DOI: 10.22363/2313-0660-2017-17-4-866-873

\section{РЕЦЕНЗИЯ НА МОНОГРАФИЮ: Baldwin R.E. The Great Convergence: Information Technology and the New Globalization. Cambridge, Massachusetts: The Belknap Press of Harvard University Press, 2016. - 344 p.}

\author{
Н.А. Волгина
}

Российский университет дружбы народов, Москва, Россия

Автор монографии - Ричард Болдуин, профессор Института высшего образования в Женеве (Graduate Institute) и директор Центра исследований экономической политики в Лондоне (Centre for Economic Policy Research - CEPR). Его научные интересы сосредоточены в области глобализации, международной торговли, регионализма и европейской интеграции. Его диссертация, которую он защищал в Массачусетском технологическом институте, была написана под научным руководством Нобелевского лауреата Пола Кругмана.

Представленная книга стала своего рода обобщением ранее предложенных Р. Болдуином идей и концепций, и с этой точки зрения она вызывает несомненный интерес и является, на наш взгляд, очень своевременной на фоне происходящих в мировой экономике противоречивых и разнонаправленных глобализационных сдвигов.

В своих работах [Baldwin 2011; 2012; 2014; Baldwin, Lopez-Gonzalez 2015] P. Болдуин, пытаясь описать современную сущность глобализации, связывает несколько понятий. Это идеи относительно unbundlings - нескольких видов «разделения» производства [Волгина 2016], на основе которых исследователь выделяет несколько этапов глобализации, в частности Старую глобализацию (Old globalization) и Новую глобализацию (New globalization), для которых характерна соответственно дивергенция и конвергенция доходов «богатых» и «бедных» стран мира.

\section{0 ТЫСЯЧ ЛЕТ ИСТОРИИ ГЛОБАЛИЗАЦИИ}

Ключевая идея подхода Р. Болдуина состоит в том, что глобализация, как мы ее понимаем сегодня, не является застывшим феноменом, она постоянно изменяется по своему качеству, и, что еще более важно, будет продолжать изменяться. 
В первой части своей книги ученый дает обзор истории глобализации, выделяя четыре ее фазы, которые, по мнению автора, охватывают последние 200 тыс. лет.

Первый этап глобализации, который, по Р. Болдуину, начался 200 тыс. лет назад, был связан с первыми передвижениями человека («миграцией») по земному шару в поисках более благоприятных условий для жизни, в первую очередь, получения пищи и тепла. На втором этапе глобализации, начало которого автор датирует десятым тысячелетием до нашей эры, продовольствие стало более доступным, народы стали занимать территории для постоянного проживания, начала развиваться «международная» торговля, правда, в самых незначительных масштабах, поскольку транспортные издержки были весьма велики. Ключевой особенностью этого периода было так называемое плато доходов населения. Весь мир (хотя Р. Болдуин говорит в основном о Европе) жил в рамках так называемой классической «мальтузианской ловушки», когда доход на душу населения никогда не повышался значительным образом, а часто даже и снижался. Мы не будем подробно останавливаться на этих этапах, отметим лишь важную деталь: по Р. Болдуину глобализация - это исторический феномен, связанный с процессами перемещения по миру чего-либо, будь то товары, идеи или люди.

Третий этап глобализации носит в книге название Старой глобализации и охватывает период с 1820 по 1990 г. Эта фаза глобализации совпадает с началом промышленной революции и связана с изобретением парового двигателя и развитием железных дорог, что привело к резкому снижению транспортных издержек и последующему росту торговли между различными частями света, а также к дивергенции доходов между богатыми и бедными странами.

На смену третьему этапу глобализации пришел четвертый - так называемая Новая глобализация. По мнению Р. Болдуина, главным стимулом смены фаз глобализации является изменение технологий (автор по преимуществу использует термин «ноу-хау»), т.е. материальной основы производства. В этом смысле мы можем проследить марксистскую составляющую взглядов Р. Болдуина. Новая глобализация была связана с прорывными информационно-коммуникационными технологиями, которые резко сократили стоимость миграции идей между странами. Все это привело к очень важным последствиям как с точки зрения международного размещения производства, так и с точки зрения распределения доходов между группами стран, чему Р. Болдуин дает название «Великая конвергенция». Р. Болдуин рассматривает последствия Новой глобализации, сравнивая их с результатами Старой глобализации. Последуем и мы этой логике.

\section{СТАРАЯ ГЛОБАЛИЗАЦИЯ: ПЕРВОЕ «РАЗДЕЛЕНИЕ» И «ВЕЛИКАЯ ДИВЕРГЕНЦИЯ»}

«Промышленная революция», с плодами которой связана Старая глобализация, существенным образом изменила отношения человечества с окружающей средой в целом и с расстояниями, в частности. Развитие паровой тяги и железных дорог облегчило транспортировку товаров, и стоимость перевозок резко упала, что 
привело к первому «разделению» производства и потребления в географическом пространстве: товары во все большей степени стали потребляться не только в тех географических локациях, где они были непосредственно произведены. Здесь следует упомянуть, что в экономическом сообществе Р. Болдуин известен, в первую очередь, благодаря именно этой идее «разделений» процесса производства, которая и лежит в основе его объяснения смены фаз глобализации.

Резкое снижение транспортных издержек позволило быстро расширить рынки сбыта за пределами Европы, которая в течение долгого времени оставалась крупнейшим производителем товаров (потом к ней присоединилась и Америка). Более того, расширение сбыта способствовало формированию промышленных кластеров в Европе и Америке и закреплению за ними роли промышленных лидеров. Как это повлияло на распределение доходов между странами?

Здесь следует сделать оговорку, относящуюся к терминологии Р. Болдуина. Мы привыкли к терминам «богатые страны», «страны Севера», «развитые страны» для характеристики промышленно развитых стран. Р. Болдуин отбирает из этой группы стран свою «великолепную семерку» (G7 — Group of Seven Nations), в которую входят США, Германия, Япония, Франция, Великобритания, Канада и Италия. Р. Болдуин полагает — и в этом с ним можно согласиться, - что именно эти страны были и продолжают оставаться мировыми технологическими лидерами, на которых приходилось около 70\% глобального экономического производства. За период Старой глобализации (примерно 170 лет) доля доходов стран «семерки» значительно возросла: с 20\% до примерно 70\% всех мировых доходов. Кроме того, к 1990 г. существовало уже огромное неравенство между богатыми и бедными странами по такому показателю, как ноу-хау на одного рабочего. Это и есть «Великая дивергенция» по терминологии Р. Болдуина.

Почему такая ситуация с дивергенцией доходов продолжалась почти 200 лет? Автор предлагает свой оригинальный ответ на этот вопрос, связанный с так называемыми сдерживающими факторами глобализации, которые действуют одновременно (three cascading constraints). Первый сдерживающий фактор, который мешает развитию процессов глобализации, - это географические расстояния и транспортные издержки в международной торговле (trade costs - cost of moving goods). Другие сдерживающие факторы - это ограничения на передвижение идей и коммуникационные издержки (communication costs - costs of moving ideas) и ограничение на передвижение людей (face-to-face costs — costs of moving people). В период Старой глобализации удалось сократить издержки на транспортировку товаров, но препятствия для перемещения идей (не говоря уже о людях) были еще слишком велики; поэтому идеи (технологии) оставались в распоряжении «семерки», по выражению Р. Болдуина.

Однако с 1990-х гг. ситуация стала меняться, доля «семерки» в мировых доходах начала стремительно падать, и этот процесс продолжается. Эта тенденция есть отражение нового этапа глобализации, который разительным образом отличается от предыдущего. Это - Новая глобализация. 


\section{НОВАЯ ГЛОБАЛИЗАЦИЯ: ВТОРОЕ «РАЗДЕЛЕНИЕ» И «ВЕЛИКАЯ КОНВЕРГЕНЦИЯ»}

Как мы отмечали выше, Р. Болдуин придерживается взгляда, что сдвиги в конфигурации мировой экономики являются отражением изменений в технологиях производства. При описании этапа Новой глобализации он утверждает, что революция в информационно-коммуникационных технологиях (ИКТ) привела не только к изменению архитектуры мировой экономики, но к «Великой конвергенции» в доходах различных групп стран. Начиная с 1990 г. (фактически Р. Болдуин имеет в виду конец ХХ столетия) вследствие распространения ИКТ издержки на межстрановое движение идей резко сократились. «Снятие» данного ограничения привело к углублению процесса глобализации. Появившаяся относительная легкость в перемещении идей-технологий, по мнению Р. Болдуина, создала исключительно благоприятные возможности для разделения производственного процесса на отдельные стадии, размещенные в странах с разным уровнем издержек, т.е. международной фрагментации производства. Это и есть второе «разделение» производства в глобальном масштабе.

Ключевыми игроками в этом процессе фрагментации стали транснациональные корпорации (ТНК). Для синхронизации и координации деятельности производственного процесса в целом ТНК наряду с оффшорингом рабочих мест были также вынуждены перемещать свои маркетинговые, управленческие и технические ноу-хау за рубеж. Данное перемещение трудоинтенсивных стадий производства из стран с высокими зарплатами в страны с более низкими зарплатами создало благоприятные условия для экономического бума в последних. Р. Болдуин называет их «шестеркой индустриализирующихся стран» - I6 (Industrializing Six), которая включает в себя Китай, Южную Корею, Индию, Польшу, Индонезию и Таиланд. Эти страны сумели стать новыми производственными локациями, которые начали «оттягивать» на себя долю мирового экономического «пирога». По Р. Болдуину, в результате второго «разделения» производства и произошла «Великая конвергенция», т.е. сближение доходов развитых и развивающихся стран, настолько значимого процесса в мировой экономике, который и дал название книге Р. Болдуина.

Автор иллюстрирует свою идею «Великой конвергенции» такими цифрами: начиная с 1990 г. доля G7 в распределении мирового дохода начала резко падать, а доля I6 - расти. В настоящее время доля развитых стран составляет менее половины, причем большая доля «потерянного пирога доходов» перешла к Китаю.

Данные процессы способствовали быстрой индустриализации стран I6 и одновременной деиндустриализации стран G7. Ключевое отличие современной индустриализации от индустриализации времен Старой глобализации - это не полная индустриализация, через которую прошли страны G7, а частичная индустриализация через присоединение к глобальным или региональным производственным сетям, где страна ответственна за те или иные звенья производства. Весьма показателен в этом плане пример Южной Кореи, которая входит в классификацию I6. 
Так, Южная Корея сумела достаточно быстро перейти от своей первоначальной модели автомобильного производства (созданной на основе импортозамещения в период Старой глобализации), где практически все комплектующие производились в стране, к созданию автомобильного производства на основе международного аутсорсинга или цепочки добавленной стоимости.

Какие еще последствия характерны для волны Новой глобализации? Наряду с индустриализацией и деиндустриализацией это одновременно есть процесс создания и распространения глобальных цепочек стоимости в обрабатывающей промышленности и сфере услуг. Часто этап Новой глобализации Р. Болдуин называет «революцией глобальных цепочек стоимости», подчеркивая исключительную важность и значимость этого явления для мировой экономики.

Революция глобальных цепочек стоимости существенным образом изменила характер конкуренции. В период Старой глобализации было уместно говорить о конкурентоспособности отдельных стран - например, США конкурировали с Китаем или Германией. Но сегодня товары уже не производятся полностью в рамках одной фабрики в одной стране. Как раз, наоборот, на повестке дня давно уже лозунг Made in the World, где идея товара разрабатывается в одной стране, различные его компоненты производятся в разных странах (включая страны с низкими трудовыми издержками), а собирается продукт для конечного потребителя в третьей стране. Как пишет Р. Болдуин, «черты промышленной конкурентоспособности в настоящее время во все большей степени определяются особенностями международного производства, а не границами отдельных стран». Другими словами, конкуренция в настоящее время идет не между национальными производителями, а между международными (региональными) производственными сетями, которые состоят из сложной комбинации региональных и глобальных цепочек. Конкуренция из внутринациональной уже стала по преимуществу кросс-национальной или международной, что налагает ряд требований к национальной экономической политике как богатых, так и бедных стран.

\section{ГЛОБАЛИЗАЦИЯ И ВЫЗОВЫ ДЛЯ НАЦИОНАЛЬНОЙ ЭКОНОМИЧЕСКОЙ ПОЛИТИКИ}

Поскольку Новая глобализация продолжает развиваться за счет быстрых технологических изменений и фрагментации производства, ее воздействие может быть весьма непредсказуемым и слабо поддающимся контролю. «Никто не может точно предсказать, какие стадии производства и какие виды работ будут затронуты в будущем, в мире, где контуры конкуренции в промышленности определяются оффшоринговыми фирмами. Глобализация может по-разному влиять на занятость рабочих в тех или иных секторах, и никто не является защищенным в этой новой ситуации», - пишет Р. Болдуин.

Новая глобализация бросает вызов национальным правительствам при проведении национальной экономической политики. Основная проблема, которую пытаются решить руководители «семерки» — как сдержать утечку тех рабочих 
мест, которые перемещаются из «богатых» стран в «бедные» в рамках формирующихся производственных систем. Парадокс состоит в том, что в подавляющем большинстве случаев проблема, характерная для периода Новой глобализации, решается (или, точнее сказать, не решается) при помощи инструментов, которые были популярны и действенны в период Старой глобализации.

До 1990 г. страны, пытающиеся провести индустриализацию своей экономики, должны были фактически начинать с нуля и выстраивать отрасли промышленности полностью на своей территории. Такой путь весьма успешно прошла Корея, а также некоторые другие страны, включая отчасти Китай. Промышленной политике импортозамещения (и экспортной ориентации) соответствовала торговая политика протекционизма; это были работающие инструменты Старой глобализации, при помощи которых достигались такие цели, как повышение национальной конкурентоспособности промышленности и рост занятости.

Работают ли эти инструменты в период Новой глобализации, в эпоху глобальных цепочек стоимости и изменившегося характера конкуренции? На этот вопрос Р. Болдуин дает однозначный ответ: нет! В эпоху Новой глобализации политика протекционизма (торгового, инвестиционного, миграционного) становится неэффективной, поскольку экспорт стран во все большей степени базируется на их импорте: чем дешевле импорт из различных звеньев цепочки, тем конкурентоспособнее «национальный» экспорт, состоящий из производства тех или иных продуктов в рамках той же цепочки стоимости.

Р. Болдуин полагает, что развитые страны должны, в первую очередь, сосредоточиться на обучении и переобучении тех рабочих, которые потеряли свои места в результате фрагментации производства, а не на попытках сохранить занятость, которую уже невозможно вернуть. Кроме того, богатые страны должны создавать четкие правила для эффективного управления инвестициями и правами на интеллектуальную собственность для того, чтобы в максимальной степени сохранить свои права на передаваемую технологию. Бедные страны должны проводить постепенную индустриализацию через встраивание в существующие цепочки стоимости, сначала опираясь на импорт технологии и привлечение зарубежных инвестиций, а уже затем - на расширение производственных мощностей в местных локациях, проводя при этом скорее политику свободной торговли, нежели чем ориентируясь на протекционизм.

\section{БУДУЩЕЕ ГЛОБАЛИЗАЦИИ}

Теория не была бы теорией, если бы не обладала прогностической функцией. В рамках предложенной парадигмы Р. Болдуин предсказывает ряд тенденций, с которыми мы столкнемся в будущем, на следующем этапе глобализации.

Ученый утверждает - и, на наш взгляд, совершенно справедливо, — что, несмотря на некоторые современные явления и факты деглобализации, процесс глобализации не затухает, он просто приобретает другие формы и вступает в свою новую фазу. Центральной идеей здесь является то, что возникают новые технологические изобретения, которые, получив широкое распространение, смогут 
«убрать» еще одно препятствие для продвижения глобализации - препятствие для передвижения людей (face-to-face costs). Что имеет в виду Р. Болдуин? Прежде всего, новейшие технологии телеприсутствия и робототехники (telerobotics and telepresence), которые уже существуют, но пока очень дороги для массового использования и слишком велики по объему и тяжеловесны (вспомним первые компьютеры!). Между тем Skype уже является широко используемой технологией, а хирургические операции на расстоянии - это также реальность, хотя и весьма редкая. Но со временем, по мнению Р. Болдуина, эти недостатки будут преодолеваться, и перемещение людей не будет носить характер исключительно физического перемещения (третье «разделение» - людей от места производства).

Каковы будут последствия протекционистской политики на приближающемся этапе глобализации, в первую очередь, для рынка труда? Если мы поставим высокие торговые барьеры для защиты наших рабочих мест в развитых странах, то занятость не будет мигрировать в другие страны, просто рабочие «человеческие» места будут заменены роботами. Этот тренд уже прослеживается в некоторых отраслях. Р. Болдуин пишет очень жестко: мы должны понять: чтобы мы ни делали, наши рабочие места не вернутся обратно; следовательно, нужны другие подходы.

Во введении к своей монографии Р. Болдуин заявляет, что ее чтение «изменит наш взгляд на глобализацию». И это совершенно справедливо. Исследователь претендует на то, чтобы представить не просто описание глобализации (таких книг написано великое множество), а предложить собственную теорию глобализации. На наш взгляд, с поставленной задачей автор справился. Стоит ли рекомендовать эту книгу для чтения? Безусловно, особенно для молодых ученых, поскольку она действительно помогает понять, в чем особенности современного этапа глобализации, как она будет видоизменяться, и какая нужна политика, чтобы минимизировать ее негативные и противоречивые последствия. В заключение хотелось бы отметить, что в 2018 г. книга выйдет в России на русском языке.

\section{БИБЛИОГРАФИЧЕСКИЙ СПИСОК}

Волгина Н.А. Макроэкономическая взаимозависимость в эпоху глобальных цепочек стоимости // Вестник Российского университета дружбы народов. Серия: Экономика. 2016. № 4. C. $133-139$.

Baldwin R. Trade and Industrialisation after Globalisation's 2nd Unbundling: How Building and Joining a Supply Chain are Different and Why it Matters // NBER Working Paper. 2011. № 17716 .

Baldwin R. WTO 2.0: Global Governance of Supply-Chain Trade // Centre for Economic Policy Research. Policy Insight. December 2012. № 64.

Baldwin R. Trade and Industrialization after Globalization's Second Unbundling: How Building and Joining a Supply Chain are Different and Why It Matters // Globalization in an Age of Crisis: Multilateral Economic Cooperation in the Twenty-First Century. Ed. by R.C. Feenstra, A.M. Taylor. Chicago: University of Chicago Press, 2014. p. 165-212.

Baldwin R., Lopez-Gonzalez J. Supply-Chain Trade: A Portrait of Global Patterns and Several Testable Hypotheses // World Economy. 2015. № 38 (11). P. 1682-1721. 
Для цитирования: Волгина Н.A. Рецензия на монографию: Baldwin R.E. The Great Convergence: Information Technology and the New Globalization. Cambridge, Massachusetts: The Belknap Press of Harvard University Press, 2016. - 344 р. // Вестник Российского университета дружбы народов. Серия: Международные отношения. 2017. Т. 17. № 4. C. 866-873. DOI: 10.22363/23130660-2017-17-4-866-873.

Сведения об авторе: Волгина Наталья Анатольевна - д-р экон. наук, профессор кафедры международных экономических отношений Российского университета дружбы народов (e-mail: volgina_na@rudn.university).

DOI: $10.22363 / 2313-0660-2017-17-4-866-873$

\title{
REVIEW OF THE BOOK: Baldwin R.E. The Great Convergence: Information Technology and the New Globalization. Cambridge, Massachusetts: The Belknap Press of Harvard University Press, 2016. - 344 p.
}

\author{
N.A. Volgina \\ Peoples' Friendship University of Russia (RUDN University), Moscow, Russia
}

\section{REFERENCES}

Baldwin, R. (2011). Trade and Industrialisation after Globalisation's 2nd Unbundling: How Building and Joining a Supply Chain are Different and Why it Matters. NBER Working Paper, 17716.

Baldwin, R. (2012). WTO 2.0: Global Governance of Supply-Chain Trade. Centre for Economic Policy Research. Policy Insight, 64.

Baldwin, R. (2014). Trade and Industrialization after Globalization's Second Unbundling: How Building and Joining a Supply Chain Are Different and Why It Matters. In: Globalization in an Age of Crisis: Multilateral Economic Cooperation in the Twenty-First Century. Ed. by R.C. Feenstra \& A.M. Taylor. Chicago: University of Chicago Press, p. 165-212.

Baldwin, R. \& Lopez-Gonzalez, J. (2015). Supply-Chain Trade: A Portrait of Global Patterns and Several Testable Hypotheses. World Economy, 38 (11), 1682-1721.

Volgina, N.A. (2016). Macroeconomic interdependence in the age of global value chains. RUDN Journal of Economics, 4, 133-139. (in Russ.).

For citations: Volgina N.A. (2017). Review of the book: Baldwin R.E. The Great Convergence: Information Technology and the New Globalization. Cambridge, Massachusetts: The Belknap Press of Harvard University Press, 2016. - 344 p. Vestnik RUDN. International Relations, 17 (4), 866 873. DOI: 10.22363/2313-0660-2017-17-4-866-873.

About the author: Volgina Natalia Anatolievna - Doctor of Economics, Professor of the Department of International Economic Relations, Peoples' Friendship University of Russia (RUDN University) (e-mail: volgina_na@rudn.university). 